\title{
Detection of Influenza C Virus Infection among Hospitalized Patients, Cameroon
}

\section{Richard Njouom, Gwladys Chavely Monamele, Burcu Ermetal, Serge Tchatchouang, Sylvie Moyo-Tetang, John W. McCauley, Rodney S. Daniels}

\begin{abstract}
Author affiliations: Centre Pasteur du Cameroon, Yaounde, Cameroon (R. Njouom, G.C. Monamele, S. Tchatchouang); The Francis Crick Institute, London, United Kingdom (B. Ermetal, J.W. McCauley, R.S. Daniels); Centre Hospitalier d'Essos, Yaounde (S. Moyo-Tetang)
\end{abstract}

DOI: https://doi.org/10.3201/eid2503.181213

We report 3 cases of influenza $C$ virus in children hospitalized with severe acute respiratory infection in Cameroon. Two of these case-patients had grave clinical manifestations, but all 3 recovered. The lack of specific antiviral drugs for influenza $\mathrm{C}$ virus highlights the need to identify and describe cases involving this virus.

$\mathrm{F}$ our types of influenza viruses are known: A, B, C, and $\mathrm{D}$ (1). Unlike influenza viruses types $\mathrm{A}$ and $\mathrm{B}$, influenza $\mathrm{C}$ viruses generally cause a mild respiratory illness (2). However, some cases of lower respiratory infections have been described in children (1-3). In recent years, severe illness due to influenza $\mathrm{C}$ virus has been reported from different geographic regions, but few data have come from Africa (3-6). Previous detection of influenza $\mathrm{C}$ virus in Cameroon reported 2 cases among 561 patients with influenza-like illness (7). We identified 3 cases of influenza $\mathrm{C}$ virus infection among hospitalized patients with severe acute respiratory infection (SARI) in Cameroon.

Respiratory samples were collected as part of the influenza surveillance system in Centre Hospitalier d'Essos, a SARI site located in the central region of Cameroon that has been involved in surveillance activity since the onset of the program in 2007. At this site, hospitalized SARI patients are screened for other respiratory pathogens, including bacteria and viruses, within the framework of an internal project running concomitantly with influenza surveillance activity since January 2017. The Cameroon National Ethics Committee gave ethics clearance for this study (document no. 2017/03/876/CE/CNERSH/SP). Each child's parent or guardian also provided written consent before sample collection. While awaiting laboratory analyses, the children received presumptive treatments, including antipyretic, antimicrobial, and antimalarial drugs. No antiviral drugs are available to treat patients with influenza $\mathrm{C}$ virus infection.
Nasopharyngeal swab specimens were collected in universal transport medium and transported to Centre Pasteur du Cameroon (Yaounde, Cameroon), where we performed analyses. We extracted RNA from the samples using a QIAamp Viral RNA Mini Kit (QIAGEN, http://www.qiagen.com) according to the manufacturer's instructions. We then analyzed samples for the presence of 33 respiratory pathogens using a real-time reverse transcription PCR (Fast-Track Respiratory Pathogens 33 PCR kit; Fast-Track Diagnostics Ltd., https:// www.fast-trackdiagnostics.com), obtained through the International Reagent Resource Program (https://www.internationalreagentresource.org). We ran the assay in an Applied Biosystems Prism 7500 thermocycler (Thermo Fisher Scientific, Inc., https://www.thermofisher.com) and considered all reactions with cycle thresholds $<37$ positive for the tested pathogens. We confirmed influenza $\mathrm{C}$ virus in samples from 3 children, 11 months, 3 years, and 4 years of age. The age distribution of the patients is compatible with reports showing that most humans acquire antibodies to influenza $\mathrm{C}$ virus early in life (3).

Other studies have shown that influenza $\mathrm{C}$ infection in infants can be severe enough to require hospitalization, compared with infection in adults $(3,8)$. All 3 patients had fever, cough, rhinorrhea, asthenia, and conjunctivitis, but 2 had additional grave clinical manifestations. One patient had exacerbated symptoms, including dyspnea, vomiting, diarrhea, and stage II coma; another had an altered general state. All 3 patients recovered.

Unlike similar studies in which influenza $C$ was identified mostly in patients with co-infections of other respiratory pathogens $(4,5)$, we did not detect co-infection in these 3 patients. Further, absence of underlying or preexisting medical conditions in the children indicates that their illnesses were solely caused by influenza $\mathrm{C}$ virus infection. Because all 3 cases were detected in the course of a project focusing on hospitalized patients in a single center, additional cases of influenza $\mathrm{C}$ infection among outpatients and hospitalized patients are likely.

We used influenza $\mathrm{C}$ sequences available in the GISAID EpiFlu database (https://www.gisaid.org) as of April 18,2018 , to design primers for whole-genome sequencing by next-generation sequencing and Sanger sequencing of the hemagglutinin-esterase (HE) gene. Based on the HE gene, 6 distinct clades of influenza $\mathrm{C}$ virus have been identified: C/Taylor/1233/47, C/Mississippi/80, C/Aichi/1/81, C/Yamagata/26/81, C/Kanagawa/1/76, and C/Sao Pau$10 / 378 / 82$ (5). Two of the patients' specimens yielded good sequence data, and maximum-likelihood HE gene phylogenetic analysis showed the Cameroon viruses cluster in the C/Sao Paolo/378/82 lineage (Figure), a dominant clade that has been detected in several other countries $(5,9,10)$.

Studies have shown variability in the circulation of influenza $\mathrm{C}$ virus, with peaks in winter and spring seasons 
$(3,4)$. These 3 cases all occurred in December 2017, possibly indicating seasonality of influenza $\mathrm{C}$ infection in Cameroon, but identification of more cases is required to confirm this hypothesis.

The recent identification of severe illnesses related to influenza $\mathrm{C}$ virus infection in Cameroon and the lack of influenza $\mathrm{C}$-specific antiviral drugs highlight the importance of integrating molecular testing for this virus into existing inpatient and outpatient sentinel surveillance systems and for in-depth studies of the epidemiology of influenza $\mathrm{C}$ viruses. This process could lead to predominant circulating strains of influenza $\mathrm{C}$ virus being included in seasonal influenza vaccines to protect vulnerable populations.

\section{Acknowledgments}

We thank the patients and their legal guardians for agreeing to be enrolled in this study.

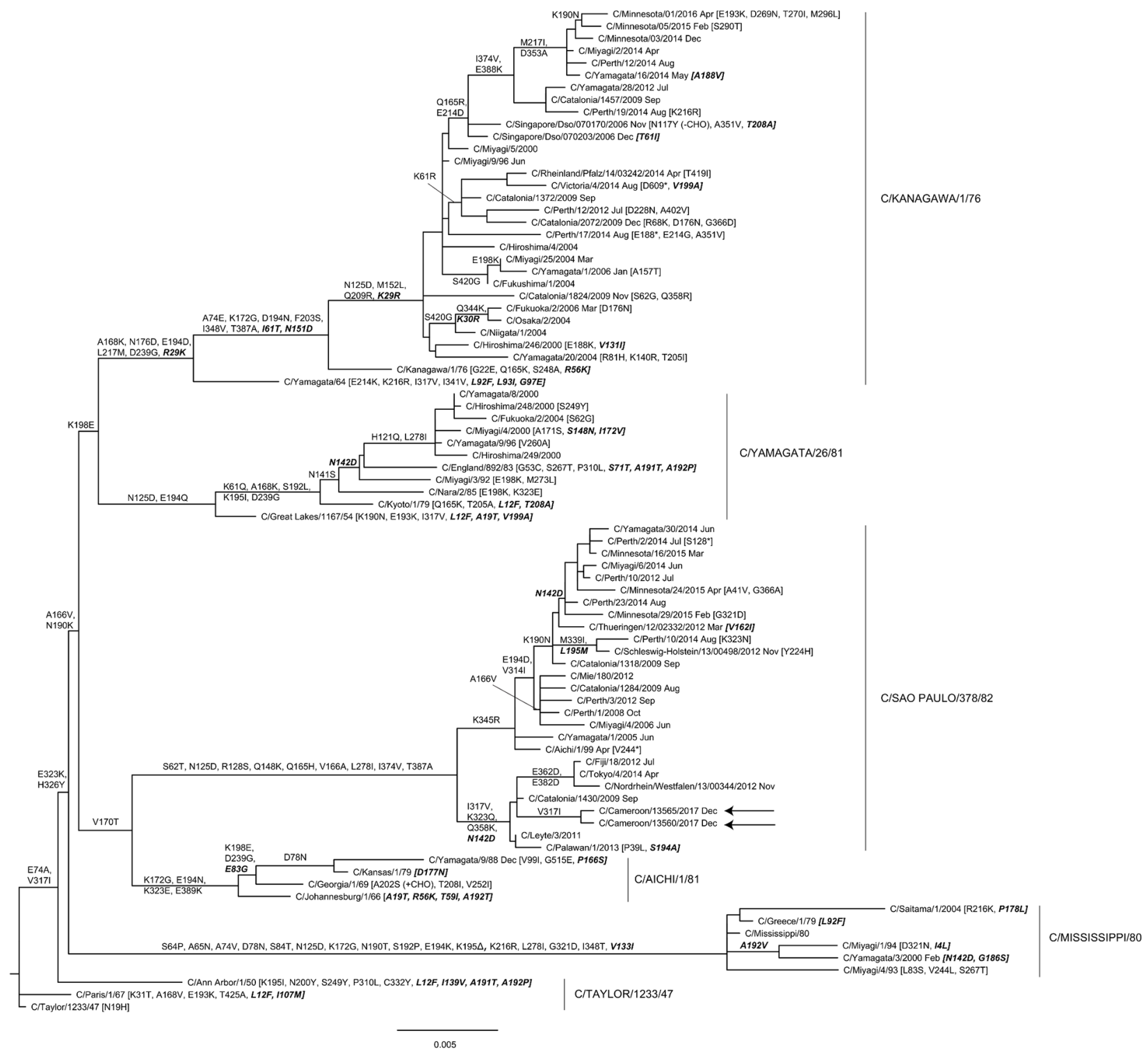

Figure. Hemagglutinin-esterase gene phylogeny for influenza C viruses detected in Cameroon compared with reference viruses. The phylogeny is based on 80 full-length open-reading frames downloaded from the GISAID EpiFlu database (https://www.gisaid.org), with signal peptide coding regions and stop codons removed, yielding products of 1,923 nt. The phylogeny was estimated by using RaxML version 8.2.X (https://sco.h-its.org/exelixis/software.html) with a general time-reversible plus gamma substitution model and then annotated with amino acid substitutions defining nodes and individual virus gene products by using treesub (https://github.com/tamuri/ treesub/blob/master/README.md). The phylogeny was visualized by using FigTree version 1.4.4 (http://tree.bio.ed.ac.uk/software/figtree). Sequences for the 2 viruses from Cameroon (arrows) have been deposited in the EpiFlu database under accession nos. EPI1259829 (C/ Cameroon/13560/2017) and EPI1259835 (C/Cameroon/13565/2017).Scale bar indicates nucleotide substitutions per site. 
This work was financially supported by the Centre Pasteur of Cameroon and the US Department of Health and Human Services grant number 6 DESP060001-01-01 via the International Network of Pasteur Institutes. Work performed at the Worldwide Influenza Centre, the Francis Crick Institute, was supported by core funding from Cancer Research UK (FC001030), the Medical Research Council (FC001030), and the Wellcome Trust (FC001030).

\section{About the Author}

Prof. Njouom is head of the Virology Department and the National Influenza Centre at the Centre Pasteur du Cameroon. His areas of interest include molecular epidemiology of hepatitis and respiratory viruses and its impact on diagnosis, treatment, and pathogenesis.

\section{References}

1. Centers for Disease Control and Prevention, National Center for Immunization and Respiratory Diseases (NCIRD). Types of influenza viruses. Influenza (Flu). 2017 Sep 27 [cited 2017 Dec 17]. https://www.cdc.gov/flu/about/viruses/types.htm

2. Wang M, Veit M. Hemagglutinin-esterase-fusion (HEF) protein of influenza C virus. Protein Cell. 2016;7:28-45. http://dx.doi.org/ 10.1007/s13238-015-0193-x

3. Matsuzaki Y, Katsushima N, Nagai Y, Shoji M, Itagaki T, Sakamoto M, et al. Clinical features of influenza $\mathrm{C}$ virus infection in children. J Infect Dis. 2006;193:1229-35. http://dx.doi.org/10.1086/502973

4. Thielen BK, Friedlander H, Bistodeau S, Shu B, Lynch B, Martin K, et al. Detection of influenza C viruses among outpatients and patients hospitalized for severe acute respiratory infection, Minnesota, 2013-2016. Clin Infect Dis. 2017:23. https://doi.org/ $10.1093 / \mathrm{cid} / \mathrm{cix} 931$

5. Jelley L, Levy A, Deng YM, Spirason N, Lang J, Buettner I, et al. Influenza C infections in Western Australia and Victoria from 2008 to 2014. Influenza Other Respi Viruses. 2016;10:455-61. http://dx.doi.org/10.1111/irv.12402

6. Onyango CO, Njeru R, Kazungu S, Achilla R, Bulimo W, Welch SR, et al. Influenza surveillance among children with pneumonia admitted to a district hospital in coastal Kenya, 2007-2010. J Infect Dis. 2012;206(Suppl 1):S61-7. http://dx.doi.org/10.1093/infdis/jis536

7. Njouom R, Yekwa EL, Cappy P, Vabret A, Boisier P, Rousset D. Viral etiology of influenza-like illnesses in Cameroon, JanuaryDecember 2009. J Infect Dis. 2012;206(Suppl 1):S29-35. http://dx.doi.org/10.1093/infdis/jis573

8. Calvo C, García-García ML, Centeno M, Pérez-Breña P, Casas I. Influenza $C$ virus infection in children, Spain. Emerg Infect Dis. 2006;12:1621-2. http://dx.doi.org/10.3201/eid1210.051170

9. Potdar VA, Hinge DD, Dakhave MR, Manchanda A, Jadhav N, Kulkarni PB, et al. Molecular detection and characterization of Influenza ' $\mathrm{C}$ ' viruses from western India. Infect Genet Evol. 2017:54:466-77. https://doi.org/10.1016/j.meegid.2017.08.005

10. Odagiri T, Matsuzaki Y, Okamoto M, Suzuki A, Saito M, Tamaki $\mathrm{R}$, et al. Isolation and characterization of influenza $\mathrm{C}$ viruses in the Philippines and Japan. J Clin Microbiol. 2015;53:847-58. http://dx.doi.org/10.1128/JCM.02628-14

Address for correspondence: Richard Njouom, Centre Pasteur du Cameroon, Virology Department, 451 Rue 205-Yaounde II, PO Box 1274, Yaounde, Cameroon; email: njouom@pasteur-yaounde.org

\section{Healthcare Provider Discrimination toward Pregnant Women with Rifampin-Resistant Tuberculosis}

\section{Marian Loveday, Sindisiwe Hlangu, Jennifer Furin}

\author{
Author affiliations: South African Medical Research Council, Cape \\ Town, South Africa (M. Loveday, S. Hlangu); Harvard Medical \\ School, Boston, Massachusetts, USA (J. Furin) \\ DOI: https://doi.org/10.3201/eid2503.181571
}

Little is known about the treatment experiences of pregnant women with rifampin-resistant tuberculosis. We conducted qualitative interviews with 10 women who had this condition; 9 reported facing discrimination from healthcare providers. Our findings underscore an urgent need to ensure a human-rights-based, patient-centered approach for women with rifampin-resistant tuberculosis who are pregnant.

$\mathrm{W}$ e report discrimination by healthcare providers toward pregnant women with rifampin-resistant tuberculosis (TB) in KwaZulu-Natal Province, South Africa. Pregnant women are at increased risk for all forms of tuberculosis (1). Experience in caring for pregnant women with rifampin-resistant TB is limited (2-4), and little is known about their experiences during treatment (5).

In 2016, a total of 3,280 patients at the King Dinuzulu Hospital Complex in KwaZulu-Natal Province were started on treatment for rifampin-resistant TB; $47 \%$ of these patients were women, many in their childbearing years (6). During 2016-2017, we conducted qualitative interviews with 10 women as part of an observational study on bedaquiline use during pregnancy, with the goal of describing treatment challenges.

All 10 of the women were postpartum and ranged in age from 22 to 37 years. The mean number of pregnancies was 3 (range 2-5). Two women were on rifampin-resistant TB treatment when they became pregnant, 7 women had rifampin-resistant TB diagnosed during pregnancy, and 1 had rifampin-resistant TB diagnosed and found out she was pregnant at the same time. Nine of the 10 women reported experiencing discrimination while accessing healthcare, either from the antenatal care providers ( 9 women), the TB care providers (4 women), or both (4 women). (Rifampinresistant TB and antenatal care services are not integrated in this setting.)

The reported discrimination faced by the women while accessing antenatal care and during delivery was largely 